\title{
The out-of-sample forecasting performance of variable parameter exchange rate models in South Africa
}

\author{
Gilbert Wesso \\ University of the Western Cape, Department of Statistics, Private Bag X17, Bellville, 7535 Republic of South Africa
}

Accepted December 1994

\begin{abstract}
In this article the out-of-sample forecasting performance of exchange rate determination is examined without imposing the restriction that coefficients are fixed over time. Both fixed and variable coefficient versions of conventional structural models are considered, with and without a lagged dependent variable. A Variable Parameter Regression (VPR) technique based on recursive application of the Kalman filter is used to improve the predictive performance of a class of monetary exchange rate models.
\end{abstract}

In hierdie artikel word die buite-steekproef vooruitskattingsvermoë van wisselkoersbepaling ondersoek, sonder om te vereis dat koëffisiënte konstant oor tyd bly. Beide die konstante en veranderlike koëffisiëntvoorstellings vir konvensionele strukturele modelle word oorweeg, met en sonder 'n sloeringsveranderlike. 'n Veranderlike Regressie Parameter (VRP). tegniek, gebaseer op die rekursiewe toepassing van die Kalman-filter word gebruik om die vooruitskattingsvermoë van 'n sekere klas van monetêre wisselkoersmodelle te bepaal.

\section{Introduction}

The debt standstill and the sanctions issue in South Africa have, inter alia, emphasized the need for empirical methodology in econometrics to deal with parameter variation over time.

One of the notable characteristics of the current international monetary system is the variability of exchange rates. In a major review of the performance of the system of generalized managed floating since 1973 , Goldstein noted that

'By almost any measure, exchange rate variability has been much greater during the period of floating rates (1973-1982) than it was during the last decade of the adjustable par value system (1963-1972)' (1984: 5).

The South African currency appears to have exhibited similar behaviour during the period since 1973. Casual inspection of the data reveals a marked increase in the variability of the rand during the 1980 s in particular. Also, Holden \& Holden (1985: 358 ), with reference to the variance of effective exchange rate indices for the rand for the period up to 1985 , noted: '... a sharp increase in exchange rate variability over the past few years'.

In this study it is tentatively proposed that the rapidly changing economic and political environment in South Africa may cause exchange rate functions to become structurally unstable. South African exchange rate models are, therefore, evaluated without imposing the restriction that the regression slopes are fixed over time. The out-of-sample forecasting performance of the variable and fixed coefficient representations of the exchange rate models are compared.

\section{Theoretical exchange rate models and prior re- search}

Although the literature has been flooded with in-sample studies of empirical exchange rate models since the breakdown of the Bretton Woods fixed-parity system in the early 1970s, systematic studies of the forecasting performance of structural or reduced-form models are relatively scarce.

Some of the more popular models which have been estimated for exchange rates are the quasi-reduced-form equations of the Frenkel-Bilson (Frenkel, 1976; Bilson, 1978), Dornbusch-Frankel (Dornbusch, 1976; Frankel, 1979) and Hooper-Morton (1982) which (for estimation purposes) can be conveniently nested as:

$$
\begin{aligned}
s= & \beta_{0}+\beta_{1}\left(m_{t}-m_{1}^{*}\right)+\beta_{2}\left(y_{t}-y_{1}^{*}\right)+\beta_{3}\left(r_{1}-r_{t}^{*}\right) \\
& +\beta_{4}\left(\pi_{t}^{e}-\pi_{t}^{e}\right)+\beta_{5}\left(T B_{t}-T B_{t}^{*}\right)+u
\end{aligned}
$$

where lower case letters indicate natural logs except for interest rates and inflation rates, and where ${ }^{*}$ indicates a foreign variable; $s$ is the spot exchange rate (e.g., $R / \$)$; $m$ is the money supply; $y$ is the industrial production or real income levels ; $r$ is the short-term nominal interest rate; $\pi_{i}^{e}$ is the long-run expected inflation rate; TB is the cumulative trade balance; and $\mathrm{u}$ is the disturbance term which may be serially correlated; lower case letters indicate natural logs except for interest rates (r) and inflation rates $\left(\pi^{e}\right)$. The betas in Equation (1) are parameters to be estimated.

Meese \& Rogoff (1983a; 1983b) estimated the following fixed coefficient versions of Equation (1):

1. Frenkel-Bilson (purchasing power parity) ${ }^{1}$ which assumes $\beta_{4}=\beta_{5}=0$.

2. Dornbusch-Frankel (slow price adjustment) which assumes $\beta_{s}=0$.

3. Hooper-Morton which is Equation (1) with unequal coefficients for the trade balances.

These models are all variants of the fixed-coefficient monetary model of exchange rates and differ only in the way they treat price adjustments. The most important (and widely criticized) element of monetary exchange rate theory is the purchasing power parity (REXPPP) doctrine.

Both the F-B and D-F models hypothesize that the exchange rate is homogeneous of degree one with respect to relative money supplies $\left(\beta_{1}=1\right)$. The F-B model, which assumes purchasing power parity also posits the restriction $\beta_{2}$ $<0, \beta_{3}>0$, and $\beta_{4}=\beta_{5}=0$. The D-F model, which allows for short-run deviations from REXPPP due to prices that respond only gradually to excess demand, hypothesizes that $\beta_{2}<0, \beta_{3}$ $<0, \beta_{4}>0$, and $\beta_{5}=0$. Schinasi \& Swamy (1989) also reported results for these models with a lagged dependent 
variable as an explanatory variable, a specification that explicitly allows for short-run deviations from long-run purchasing power parity.

The above models represent an important class of empirically testable models of exchange rate determination. Extensive in-sample studies of the model properties have appeared in the literature. These in-sample studies have shown quite satisfactory fits (see e.g., Bilson, 1978; and Frankel, 1979). Meese \& Rogoff (1983a), for example, used monthly data over the period March 1973 to June 1981. The fixed-coefficient version of Equation (1) was initially estimated for exchange rates using data up to October 1976. Forecasts were generated for four different horisons using actual realizations of all explanatory variables for a prediction period. Then the data for November 1976 were added to the sample, and the parameters for each model were re-estimated. New forecasts were generated for the same horisons, etc. In the MeeseRogoff studies, this sequential estimation yielded fixedstep-ahead forecasts which were generally inferior to those given by the random-walk model. The estimation procedures used in their sequential estimation were ordinary least squares (correcting for scrial correlation in the error term), and Fair's (1974) instrumental variable technique. Meese \& Rogoff also considered six univariate time series models involving a variety of prefiltering techniques and lag length selection criteria, a random walk with drift parameter, and an unconstrained vector autoregression. None could outpredict the random model $s_{t}=s_{t-1},+a_{1}$, where $a_{t}$ represents white noise with zero mean and constant variance.

Wolff (1987) and Schinasi \& Swamy (1989) went further in focussing on predictive testing in the context of varyingparameter versions of the above monetary exchange rates models. Their empirical results provided new evidence on the predictive performance of these models and indicated that a certain degree of parameter instability was indeed present.

\section{Causes of parameter variation in exchange rate models}

The seminal work of Meese \& Rogoff (1983) casts serious doubt on the ability of international macroeconomic theory to predict exchange rate movements. These studies concluded that linear fixed-coefficient regressions of exchange rates on variables such as relative money supplies, indices of industrial productions, short-term interest rates, and trade balances, failed to match the out-of-sample forecasting performance of a simple random-walk model, even though the models ' torecasts were based on actual, realized values of future explanatory variables. Meese \& Rogoff's main results were reported as

'robust to a variety of (fixed coefficient) estimation techniques, specifications of the underlying money demand functions, alternative serial correlation or lagged adjustment corrections, and measures of forecast accuracy' (1985: 5).

One might be tempted to conclude from these studies that economic variables convey little or no useful information about exchange rate movements. However, a number of potential explanations for the unimpressive out-of-sampling performance of the models have been offered in the literature
(Isard, 1983; Meese \& Rogoff, 1983; Saidi, 1983). Some important ones are the following:

1. Even if the explanatory variables capture all information used by traders, there is no reason to believe information is used in the same way over all policy regimes and over all time horizons; parameters can change over time. As argued by Swamy \& Schinasi (1989), sequential estimation of fixed coefficient regression ('rolling') is not the appropriate technique for capturing variations in coefficients over time.

2. Many of the empirical studies have assumed that coefficients are fixed over the relevant sample period. Most of this literature decisively rejects economic theory as having any ability to produce accurate predictions. Yet, it would be unreasonable to reject theories that have been tested on only a very limited subset of models, namely specific linear or non-linear fixed coefficient models. These models may have performed poorly because of omitted variables, or because of incorrect functional forms. Wolff (1987), for example, argued that Meese \& Rogoff performed joint tests of the out-of-sample validity of the exchange rate models and the demand functions that they implicitly specified, and that it may well be that their rejections were, at least in part, due to the inadequately specified demand functions; on the other hand, linear fixed-coefficient exchange rate models are a very limited subset of statistical representations of the underlying economic theory and the limitations of linearity are well known. Unfortunately, there is a paucity of exchange rate theory suggesting what type of non-linearities may exist (see Schinasi \& Swamy, 1989), not because economists believe the world is linear, but because linearity is a practical simplifying assumption. One way of detecting deviations from linearity is to relax the assumption of fixed coefficients and to examine whether forecasting performance is improved.

3. At the high level of aggregation of exchange rates, there is little reason to believe that behavioural parameters are fixed. There is a wide diversity of participants in foreign exchange markets with relatively small and highly variable market shares. Even if each participant reacted to macroeconomic developments according to a stable fixed coefficient reaction function, it is difficult to argue that macroeconomic variables would be related to exchange rates by a simple fixed coefficient relationship, without also assuming that the individual reaction functions are identical.

4. Factors leading to changes in the long-run real exchange rate (such as changes in oil prices, global trade patterns, etc.) may lead to instability in the parameters of the class of structural exchange rate models.

\section{A variable parameter regression technique}

A variety of statistical models have been developed for situations where the coefficients of the general linear model are assumed to vary in a systematic way across observations. The choice of a model depends on, amongst other things, the nature of the available data, the assumptions and restrictions that apply, as well as the existence of an operational method of estimating these models. 
Variable parameter regression (VPR) is a generalization of dynamic regression, useful for the advanced forecaster in regression problems where some of the coefficients are known to be time-varying. In this case, the VPR model extends the conventional regression model by allowing some of the coefficients of the model to be unobserved time series, which must be estimated in its entirety in order to fit the model and calculate forecasts.

Watson \& Engle (1983) discussed general approaches to the estimation problem for unobservable variables, with particular reference to the VPR problem. The essence of their approach is to formulate the economic model as an engineering state-space model and to use the Kalman filter recursive algorithm to generate the likelihood function via a combination of the EM (Estimation and Maximization) technique (see Dempster, Laird \& Rubin, 1977) and the method of scoring (Pagan, 1980). The Watson-Engle model can either be applied in cases where the parameters of the regression model follow a random-walk process or an AR(1) process.

One should, however, always be sure that a conventional regression model has been specified that is adequate except for the time variation in one or more parameters. If the nonvarying part of the model is not correctly specified, the algorithm will force the time varying coefficient into surrogate behaviour. VPR should therefore only be used when it is conceptually reasonable that one or more parameters are stochastically time varying and when specific statistical tests reject the null hypothesis of fixed parameters. Two such tests, the Watson-Davies (see Watson \& Engle, 1985) and the Chow (1960) test are recommended.

If the coefficients of a model are suspected to change abruptly at discrete time periods, the Chow test should be used. If the test rejects the null hypothesis, one might then explore conventional regressions involving dummy variables that turn on or off at discrete points in time. Deterministic variation of parameters can always be treated by constructing appropriate variables under conventional regression. VPR should be avoided in these cases. In fact, Goodrich (1990) recommended that one should always try a more elaborately specified conventional regression, and only after convincing yourself that some of the regression coefficients are truly varying over time, one should proceed to VPR.

On the other hand, VPR is most suitable when one or more of the coefficients vary smoothly in time. Although these changes might be generated by some economic process, it is reasonable to substitute an ARIMA surrogate for the true economic process. In the Watson-Davies test, the null hypothesis implies that the coefficients are constant while the alternative state that they are varying via some AR(1) process with unknown parameter. Even though this test is complex and fairly expensive in terms of computer time (because the AR[1] parameter defined under the alternative, is not defined under the null), Goodrich (1990) stated that, experimentally, the test appears to be powerful and very useful.

\section{Forecasting strategy}

It is conventional in applied situations to assess the usefulness of a forecasting model and to choose among competing models on the basis of forecasting performance. This is also widely done in the econometrics literature, and the root mean squared error (RMSE) statistic is usually of central interest for comparison purposes (see e.g., Fair, 1974; Machack, Spivey \& Wrobleski, 1985; and Swamy, Conway \& Le Blanc, 1988; 1989).

The residuals, residual autocorrelations, mean square errors, etc. are used to select models at the diagnostic checking stage. Diagnostic checking, which is part of the modelling phase, is very useful. However, the residuals or the historical one-step-ahead forecast errors depend on estimates of unknown parameters. Thus, the selected model might fit the data from which the estimates are calculated very well. However, when the forecasts are compared with out-of-sample data, the agreement need not be as good. Hence, comparisons of forecasts with actual observations can be useful additional tools for model evaluation and selection (see Box \& Tiao, 1976).

An initial part of the time series is used for the estimation of variable and fixed coefficient versions of the structural models while the remaining period is used to generate one-stepahead or multi-step-ahead forecasts of the out-of-sample values of the dependent variable. This holdout period is then used for forecast evaluation and model comparison. In long time series one can use the initial part for model construction and the remaining part as a hold-out period for forecast evaluation and comparison. The choice of where to begin forecasting is mainly guided by the desire to have sufficient degrees of freedom available for initial parameter estimates of all the models. In this study multi-step-ahead forecasts are computed using models with fixed and stochastically varying coefficients, extending the work of Meese \& Rogoff without duplicating their efforts.

Besides the above summary statistics for measuring out-ofsample forecast accuracy, use is made of the Akaike Information Criterion (AIC) and the Bayes Information Criterion statistics to select the model that is likely to forecast (out-ofsample) most accurately for a particular data set (see Koehler \& Murphree, 1986). The two statistics differ in how severely they penalize model complexity. The BIC punishes complexity more severely and research has shown that the BIC leads to better out-of-sample forecasts than AIC. The SEE statistic is the one-step-ahead forecast error for the model over the historical period. For regression this equals the standard error of estimation (SEE).

Although out-of-sample comparisons have considerable intuitive appeal, formal tests of whether these differences are statistically significant generally require restrictive assumptions (see Granger \& Newbold, 1977: 281) But this limitation to the experimental design does not turn out to be crucial for the interpretation of the results.

\section{Empirical results}

\section{Introduction}

In a study by Wesso (1994) recursive residual and log likelihood techniques are combined to detect and locate shift points. Two monthly exchange rate functions for the South African economy are re-estimated and tested for structural stability over the period 1970 to 1992 . It is shown that a substantial number of exchange rate models fail one or more tests for structural stability. 
Consequently, the feasibility of modelling parameter instability in econometric models is investigated. The re-estimated parameters are reported with the corresponding t-statistic in parenthesis. A $5 \%$ level of significance is used in all cases. A key to the symbols used appears in Appendix A.

No claim is made that the functions selected cover the full population of functions of this nature, nor that the functions selected form a random sample of all possible functions. Rather the technique of accessibility sampling is used and the most important criterion in selecting a particular function was the availability of data which allowed for the re-estimation of the equation.

The chosen equation is re-estimated, with the latest published data, by means of ordinary least squares (OLS) techniques. Variable parameter regression (VPR) techniques are applied afterwards if an equation proved to be structurally unstable. The period under study is from 1970M1 to 1992M12.

The empirical results are offered as an additional warning that conventional statistics such as $\mathbf{R}^{2}$ or $\mathrm{t}$-ratios may give misleading information on the appropriateness of econometric models. This is in line with the arguments of Lovell (1983: 1-12), who points out the ease with which high t-values can be obtained without there being any relationship between variables whatsoever. Supplementing conventional regression output with a battery of specification tests therefore will make it harder for results that are the product (whether intentional or unwittingly) of some data mining process, to appear 'significant'

\section{Model comparison and evaluation}

A number of variables are entered into fixed and random coefficient models in a series of exploratory stages, designed to identify the statistically significant determinants of exchange rates. The models are selected on the basis of studies reported in the literature and the author's intuition. The series of stages could be defined as follows:

Stage 1: The estimation of a fixed coefficient model with ordinary least squares (OLS) techniques and in which a model-builder at some stage had some trust.

Stage 2: Improving the Stage 1 specification, using OLS techniques, so that it is acceptable on both economic, theoretical and statistical grounds.

Stage 3: A varying parameter process is defined for only one coefficient at a time (due to limited computer memory). The Watson-Davies test indicates the most significant timevarying parameter during the second stage of estimation. The Stage 2 function is then re-estimated using an appropriate VPR technique. Experimentation with changing parameters is performed even if parameters do not show up to be changing smoothly over time.

For some of the equations the Cochrane-Orcutt correction for serial correlation is used when necessary. The results for Stages 1 to 3 are summarized in Table 1 for exchange rate models. This table contains the name of the dependent variable, the names of the independent variables and a statistical report at the bottom of the table. Also reported are the coefficient estimates with their respective $t$-values in parenthesis for each of the stages. The time period referred to in the table is the period of fit which represents a subset of the historical data. The latest part of the sample data are withheld to allow for ex-post forecast evaluations. A total of three stages for exchange rate functions are investigated using monthly data at constant 1985 prices.

To tie up with a study by Meese \& Rogoff (1983a) the Rand/US Dollar exchange rate (REX12) is defined as a function of the German Mark/US Dollar exchange rate (REXDM\$) and the purchasing power parity rate (REXPPP), therefore representing a Frenkel-Bilson type of exchange rate model.

In the case of the Stage 1 model the $t$-statistics indicate that all the estimated parameters are statistically significant at the $5 \%$ level of significance. Diagnostic checking on the randomness of the residuals shows patterns of autocorrelation. The equation is re-estimated in Stage 2 by using the CochraneOrcutt estimation procedure after a trend and a lagged dependent variable are included. All parameter estimates are significant and appear with a priori correct signs. The adjusted correlation coefficient also improved from 0.923 in Stage 1 to 0.994 in Stage 2. Economically, statistically and econometrically speaking, everything appears to be in order. even allowing for the bias in the Durbin-Watson statistic caused by the lagged dependent variable.

Table 1 Regression results for fixed and variable parameter exchange rate model E-1

\begin{tabular}{|c|c|c|c|c|}
\hline \multirow[b]{2}{*}{ Variables } & \multicolumn{3}{|c|}{ Coefficient estimates } & \multirow{2}{*}{$\begin{array}{c}\text { Watson-Davies* } \\
\text { VPR test }\end{array}$} \\
\hline & Stage 1 & Stage 2 & Stage 3 & \\
\hline$\overline{\mathrm{REX} 12}$ & Endogenous & Endogenous & Endogenous & \\
\hline \multirow[t]{2}{*}{ CONSTANT } & -0.903 & -17.296 & -100.717 & 0.550 \\
\hline & $(-9.383)$ & $(-3.410)$ & $(-1.462)$ & $(0.457)$ \\
\hline \multirow[t]{2}{*}{ REXDMS } & 0.210 & 0.061 & 0.105 & - \\
\hline & $(7.387)$ & (3.784) & $(2.237)$ & - \\
\hline \multirow[t]{2}{*}{ REXPPP } & 1.419 & 0.101 & Random & 0.550 \\
\hline & (47.892) & $(2.369)$ & walk & $(0.993)$ \\
\hline \multirow[t]{2}{*}{$\operatorname{REX} 12(-1)$} & - & 0.885 & 0.584 & 0.550 \\
\hline & - & (26.593) & $(5.6 ! 9)$ & $(1.000)$ \\
\hline \multirow[t]{2}{*}{ TREND } & - & 0.009 & 0.051 & - \\
\hline & - & (3.389) & (1.463) & - \\
\hline \multirow[t]{2}{*}{$\operatorname{AUTO}(-1)$} & - & 0.338 & -0.141 & - \\
\hline & - & $(4.731)$ & $(-1.229)$ & - \\
\hline \multirow[t]{2}{*}{ VAR Error } & - & - & $4.872 \mathrm{E}-007$ & - \\
\hline & - & - & $(0.003)$ & - \\
\hline \multirow[t]{2}{*}{ VAR REXPPP } & - & - & 0.002 & - \\
\hline & - & - & $(4.493)$ & - \\
\hline \multicolumn{5}{|c|}{ Statistical report: } \\
\hline $\mathrm{k}^{2}$ & 0.923 & 0.994 & 0.994 & - \\
\hline $\mathbf{R}^{2}$ & 0.924 & 0.994 & 0.994 & - \\
\hline DW & 0.092 & 2.024 & 2.293 & - \\
\hline SEE & 0.209 & 0.058 & 0.061 & - \\
\hline
\end{tabular}

Estimation Period: 1970M2-1991M12

* Watson-Davies VPR test performed during second stage of estimation 
Although everything seems to be in order with the Stage 2 exchange rate model, when a number of structural stability tests are performed on this equation, most of them point at structural instability (see Wesso, 1994: Chapter 13). The next step is, therefore, to estimate the regression parameters using VPR techniques. The Stage 3 model combines a traditional dynamic model with lagged variables and a random-walk parameter model. It will be seen in the next section that, although the estimates of some of the parameters turned out to be insignificant at a 5\% level of significance, allowing for parameter variation leads to an improved forecasting performance relative to the fixed coefficient conventional dynamic model. Furthermore, the fact that the variance parameter of REXPPP turns out to be highly significant, gives one reason to believe that the parameter of the purchasing power parity rate is changing over time. This is in line with Pentecost's (1993: 36) remark that deviations from REXPPP is caused by structural change in the economies of industrialized countries away from international trade towards the (non-tradeable) services production; and that shocks alter relative prices of non-tradeables. Although the phi coefficient is not close to unity, a random- walk model is selected because of its superior results. Except for a few insignificant parameter estimates, all remaining statistics are satisfactory which point at a well estimated VPR model.

\section{Forecasts evaluation}

To examine the forecasting properties the models are estimated with OLS, GLS, and VPR estimation techniques, which cover the three stages of estimation discussed earlier. The RMSE, together with other forecasting criteria, are used to compare the forecasting performance of each model. The model with the smallest out-of-sample RMSE is chosen to be the best in predicting future values for the dependent variable.

The structural stability tests have shown that some of the regression parameters for the exchange rate models have not been constant over time, but rather follow some stochastic pattern. Empirical regularity suggests that this information should be effectively incorporated into the forecasting process. To elucidate this, the three stages of estimation is applied.

All the competing models are estimated with monthly data which start in January 1970 and extend through December 1991, including the floating rate period which began in 1973 . Ex-post forecasts are generated for each month during 1992 using the actual realizations of all explanatory variables for the prediction period.

It is found that when the forecasting performance of the different model-stages are compared, using goodness-of-fit criteria over the estimated period, the VPR models do not necessarily perform better than its fixed coefficient counterparts. The situation is, however, different when these criteria are evaluated over the extended forecasting period.

The results are summarized in Tables 2-4. Table 2 compares the forecasting performance of fixed coefficient models and the VPR model over the sample period.

$A$ trend and a lagged dependent variable are included in the Stage 2 and 3 models with both models corrected for firstorder serial correlation. The Stage 3 model combines a traditional dynamic model with lagged variables and a VPR model. The structural models with lagged dependent varia-
Table 2 Forecast evaluation statistics over historic period for an exchange rate function

\begin{tabular}{lcccccc}
\hline $\begin{array}{l}\text { Dependent } \\
\text { variable }\end{array}$ & Model & $\begin{array}{l}\text { Fitting } \\
\text { period }\end{array}$ & Stage & AIC & BIC & RMSE \\
\hline REX12 & E-1 & 197OM2- & 1 & 0.210 & 0.214 & 0.208 \\
& & 1991M12 & 2 & 0.058 & 0.061 & 0.057 \\
& & & 3 & 0.066 & 0.070 & 0.064 \\
\hline
\end{tabular}

bles are 'nested' models in the sense that the structural models with lagged dependent variables can be viewed as a model in which lagged exchange rates and economic variables are allowed to 'explain' the spot exchange rate. If the structural model outperforms the VPR model over the sample period, then one can attribute this superior performance to the informational content of the economic variables included and the economic theory that suggested these variables. This could be the reason why the Stage 2 model appears to fit the data best over the sample period judging by the values of the AIC, BIC and RMSE summary statistics. Although the Watson-Davies test indicates a significant time-varying coefficient for the purchasing power parity rate (sec Table 1 ), the well estimated conventional model still outperforms the VPR model in fitting the sample data. The AIC and BIC also indicate that the fixed coefficient model of the second stage will perform better than the VPR model of Stage 3.

Table 3 as opposed to Table 2 contains surprising results regarding the RMSE statistics for an ex-post forecasting period of 12 months. The results in Table 3, however, are the more important and decisive results. It can be seen that allowing for parameter variation leads to $38 \%$ improvement in forecasting performance relative to the conventional dynamic model without parameter variation.

The forecasting errors of the various models are listed in Table 4. Note that the multi-step-ahead forecast of the VPR model is far superior to the multi-step-ahead forecasts of the original fixed coefficient model (of Stage 1) without the lagged dependent variable.

The forecasting errors are relatively large and positive in the case of the Stage 1 model, indicating a systematically overprediction over the course of the extended sample. The reason for the overprediction could be because of the fact that structural models do tend to go systematically off track if no serial correlation is allowed for (see Table 1).

Because each of the two fixed-coefficient models presented - one with and the other one without a lagged dependent variable - use different sets of information in generating multistep-ahead predictions, one has to be very careful in comparing their forecasting performance. Although the equations with a lagged dependent variable as an explanatory variable (as in Stages 2 and 3) represent a multi-step-ahead forecast, in the sense that it does not use data beyond period $\mathrm{T}$ (indicated by the vertical line in Figure 1) to estimate parameters used for prediction, its vector $x^{1}{ }_{T+1}$ does contain the observation on the lagged dependent variable for the time periods beyond $\mathrm{T}$.

The goodness-of-fit graph in Figure 1 corroborates the bad performance of the original fixed coefficient model. It can be seen that the VPR model of Stage 3 performs much better in fitting the sample data than the Stage 1 model for exchange 
Table 3 Out-of-sample RMSE of varying and fixed coefficient estimators for an exchange rate function

\begin{tabular}{lcccccc}
\hline $\begin{array}{l}\text { Dependent } \\
\text { variable }\end{array}$ & $\begin{array}{c}\text { Fitting } \\
\text { period }\end{array}$ & $\begin{array}{c}\text { Forecasting } \\
\text { period }\end{array}$ & 1 & $\begin{array}{c}\text { Stage } \\
2\end{array}$ & 3 & $\begin{array}{c}\text { Improvement over best } \\
\text { fixed alternative (\%) }\end{array}$ \\
\hline REX12 & 1970M2- & 1992Ml & 0.609 & 0.167 & 0.103 & 38 \\
& $1991 \mathrm{M} 12$ & $1992 \mathrm{M} 12$ & & & & \\
\hline
\end{tabular}

Table 4 Forecast errors of the multi-step-ahead forecast for exchange rate function

\begin{tabular}{lcccccc}
$\begin{array}{l}\text { Dependent } \\
\text { variable }\end{array}$ & Model & $\begin{array}{c}\text { Time } \\
\text { period }\end{array}$ & Actual & Stage 1 & Stage 2 & Stage 3 \\
\hline REX12 & E-I & 1992M1 & 2.779 & -0.551 & -0.010 & 0.023 \\
& & M2 & 2.815 & -0.548 & -0.012 & 0.058 \\
& & M3 & 2.881 & -0.503 & -0.011 & 0.115 \\
& & M4 & 2.878 & -0.546 & -0.035 & 0.105 \\
& & M5 & 2.847 & -0.597 & -0.105 & 0.069 \\
& & M6 & 2.810 & -0.653 & -0.178 & 0.029 \\
& & M7 & 2.753 & -0.712 & -0.261 & -0.020 \\
& & M8 & 2.763 & -0.733 & -0.277 & -0.010 \\
& & M9 & 2.798 & -0.713 & -0.268 & 0.022 \\
& & M10 & 2.884 & -0.639 & -0.208 & 0.097 \\
& M11 & 2.976 & -0.535 & -0.120 & 0.197 \\
\hline RMSE & & & & 0.609 & 0.167 & 0.103 \\
\hline
\end{tabular}

rates.

The dominance of the VPR model over the Stage 2 model, judging by the forecasting error, remains when forecasting begins in May 1992 and ends in October 1992 (see Table 4). The RMSE further indicates that when coefficients are allowed to change period by period, multi-step-ahead forecasts of the VPR model outperform multi-step-ahead forecasts of the fixed coefficient model.

The forecasting error squared over the fitted and extended sample is presented in Figure 2. These errors are particularly large during the time when the government announced a debt 'standstill' on the repayment of a major part of South Africa's foreign debt in 1985. It was a time earmarked with general political instability and an international debt crisis. South Africa also experienced a sharp depreciation of the Rand against the US Dollar at the time.

Although the results presented above do not answer the question of whether the VPR model for exchange rates is significantly better than the other models in the primary criterion, root mean square error, the finding that the VPR model almost invariably has the lowest RMSE over all horisons,

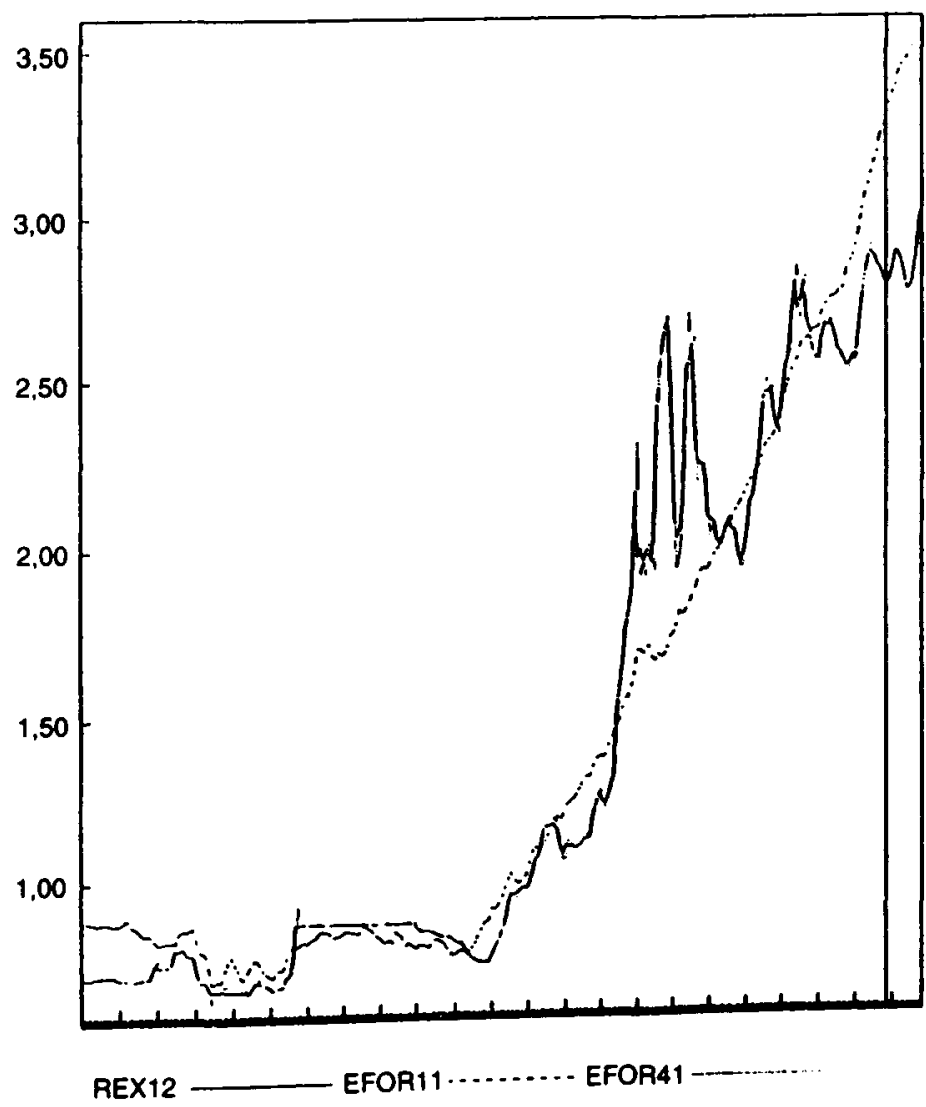

Figure 1 The goodness-of-fit track record for model E-1, stages 1 and 4 


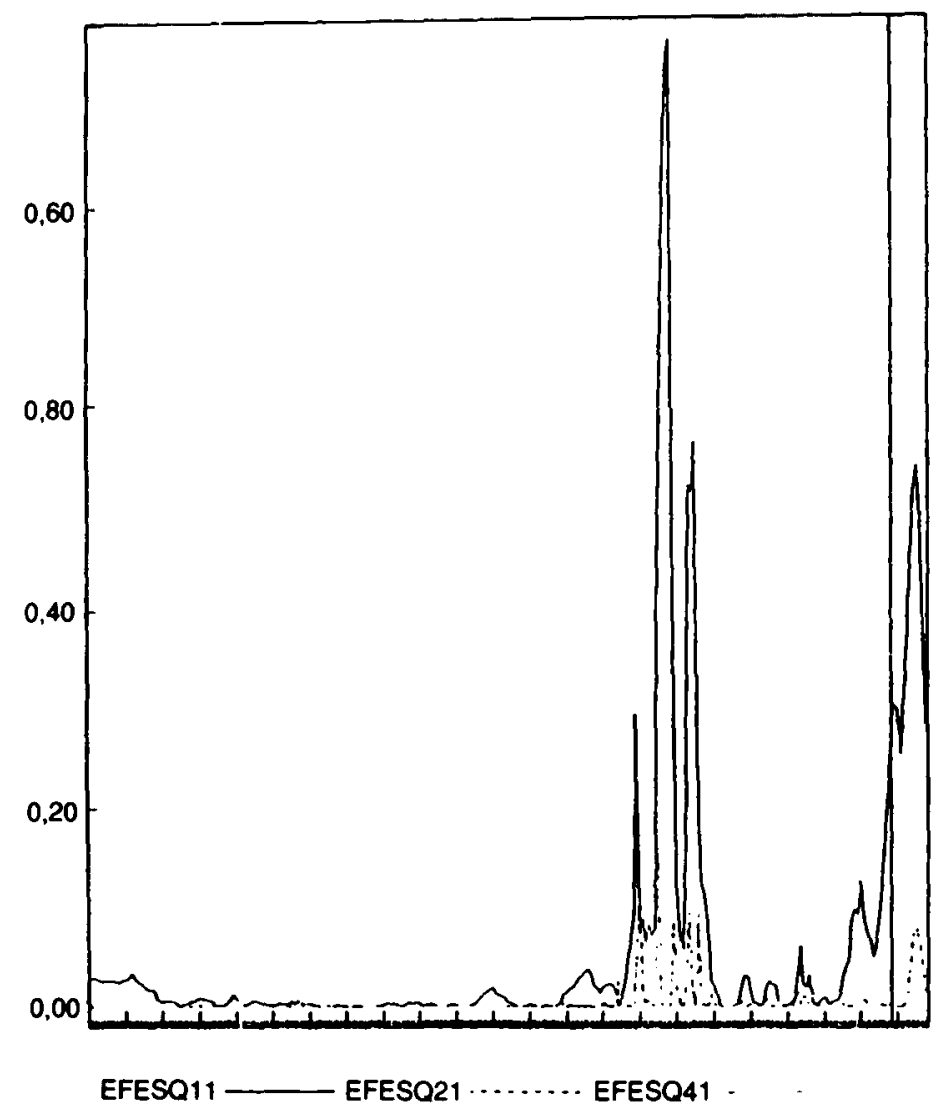

Figure 2 Forecast errors squared for model E-1, stages 1,2 and 4

causes one to unambiguously assert that the fixed coefficient models do not perform significantly better in ex-post forecasting performance than the VPR models in this study.

\section{Conclusion}

The main result of this study is that once one is willing to relax the assumption of fixed regression slopes, it is possible to estimate structural models of exchange rate determination which perform better than the conventional model in predicting out-of-sample values of exchange rates.

With respect to monetary-type models of exchange rate determination, the findings indicate that on average they leave a lot to be desired as descriptors of the behaviour of relative prices of the South African currency during the recent floating exchange rate period. This research, therefore, suggests that the time-series properties of the parameters should be exploited effectively and be incorporated into the exchange rate models to improve predictions. Because there are many explanations for parameter variability, one cannot identify the specific reason or reasons determining why the coefficients in a time-varying parameter model are nonconstant.

Reasons for structural instability are, therefore, given only on a speculative basis. One would have preferred reporting results that explain the variability of coefficients with sound and rigorous economic principles. But until economic theory postulates empirically implementable hypotheses addressing why exchange markets are so volatile and why model coefficients vary over time, one can at least examine the type of sto- chastic coefficient models presented here before rejecting existing exchange rate models out of hand.

\section{Note}

1. Bilson (1978: 62) defined purchasing power parity as the ratio between domestic and foreign consumer price indices.

\section{References}

Bilson, J.F.O. 1978. 'Rational expectations and the exchange rate'. In Frenkel, J. \& Johnson, H. (Eds.). The economics of exchange rates. MA: Addison-Wesley Press.

Box, G.E.P. \& Tiao, G.C. 1975. 'Intervention analysis with applications to economic and environmental problems', Journal of the American Statistical Association, Vol. 70: 70-79.

Chow, G.C. 1960. 'Tests of equality between sets of coefficients in two linear regressions', Econometrica, Vol. 28: 591-605.

Dempster, A.P., Laird, N.M. \& Rubin, D.B. 1977. 'Maximum likelihood from incomplete data via the EM algorithm', Journal of the Royal Statistical Society B, Vol. 39: 1-38.

Dornbusch, R. 1976. 'Expectations and exchange rate dynamics', Journal of Political Economy, Vol. 84: 1161-1176.

Fair, R. 1974. 'An evaluation of a short-run forecasting model', Intermational Economic Review, Vol. 15: 285-304.

Frankel, J.A. 1979. 'On the mark: a theory of floating exchange rates based on real interest differentials', American Economic Review, Vol. 69: 610-622.

Frenkel, J.A. 1976. 'A monetary approach to the exchange rate: doctrinal aspects and empirical evidence', Scandinavian Journal of Economics, Vol. 78: 200-224.

Goldstein, M. 1984. 'The exchange rate system: Lessons of the past and options for the future: astudy by the research department of 
the international monetary fund', Occasional Paper No. 30 , Washington, D.C.

Goodrich, R.L. 1990. Applied Statistical Forecasting. Business Forecast Systems. Belmont, MA.

Granger, C.W.J. \& Newbold, P. 1977. Forecasting economic time series, 2nd edition. New York: Academic Press.

Holden, M.G. \& Holden, P. 1985. 'Alternative measures of exchange rates and exchange rate policy in South Africa', The South African Journal of Economics, Vol. 53: 351-365.

Hooper, P. \& Morton, J. 1982. 'Fluctuations in the dollar: amodel of nominal and real exchange rate determination', Journal of International Money and Finance, Vol. 1: 39-56.

Isard, P. 1983. 'What's wrong with empirical exchange rate models: some critical issues and new directions', Intermational Finance Discussion Papers No. 226, Federal Reserve Board, Washington, D.C.

Kahn, B. 1991. 'The crisis and South Africa's balance of payments'. In Gelb, S. (Ed.). South Africa's economic crisis. Cape Town: David Philip, pp 59-87.

Koehler, A.B. \& Murphree, E.S. 1986. A comparison of the AlC and $B I C$ on empirical data. Sixth International Symposium on Forecasting, Amsterdam.

Lovell, M.C. 1983. 'Data mining', The Economic Review, Vol. 65: 1-2.

Machack J.A., Spivey, W.A. \& Wrobleski, W.J. 1985. 'A framework for time varying parameter regression modeling', Journal of Business and Economic Statistics, Vol. 3: 104-111.

Meese, R.A. \& Rogoff, E.C. 1983a. 'Empirical exchange rate models of the seventies: do they fit out of sample?', Journal of International Economics, Vol. 14: 3-24.

Meese, R.A. \& Rogoff, K. 1983b. 'The out-of-sample failure of empirical exchange rate models: sampling error or misspecification?' In Frenkel, J.A. (Ed.). Exchange rates and international macroeconomics. Chicago: University of Chicago Press.

Meese, R.A. \& Rogoff, K. '1985. Was it real? The exchange rate interest differential relation, 1973-1984', International Finance Discussion Paper No. 268, Federal Reserve Board, Washington, D.C.

Pagan, A.R. 1980. Some identification and estimation results for regression models with stochastically varying coefficients', Journal of Econometrics, Vol. 13: 341-363.

Pentecost, E.J. 1993. Exchange rate dynamics. Hants: Edward Algar. Saidi, N. 1983. 'Comment'. In Frenkel, J.A. (Ed.). Exchange rates and international macroeconomics. Chicago: University of Chicago Press, pp 105-109.

Schinasi, G.J. \& Swamy, P.A.V.B. 1989. 'The out-of-sample forecasting performance of exchange rate models when coefficients are allowed to change', Journal of International Money dnd Finance, Vol. 8: 375-390.

Swamy, P.A.V.B., Conway, R.K. \& Le Blanc, M.R. 1989. 'The stochastic coefficient approach to econometric modeling, Part III: estimation, stability testing, and prediction', The Journal of Agricultural Economics Research, Vol. 40: 4-36.

Watson, M.W. \& Engle, R.F. 1983. 'Alternative algorithms for the estimation of dynamic factor, inimic and varying coefficient regressionmodels', Journal of Econometrics, Vol. 23, 385-400.

Watson, M.W. \& Engle, R.F. 1985. 'Testing for regression coefficient stability with a stationary AR(l) altemative', Review of Economics and Statistics, Vol. 67: 341-346.

Wesso, G.R. 1994. The econometrics of structural change: statistical analysis and forecasting in the context of the South African economy, Unpublished Ph.D. Thesis, University of the Western Cape, Bellville.

Wolff, C.C.P. 1987. 'Time-varying parameters and the out-of-sample forecasting performance of structural exchange rate models', Journal of Business and Economic Statistics, Vol. 5: 87-98.

\section{Appendix A}

\section{Notes to abbreviations used in the text}

AUTO(1) Autocorrelationcoefficient, lagged one period

DW Durbin-Watson d statistic

E-n Exchange rate function number $n$

EFESQ(jn) Forecasting error squared for exchange rate function number $\mathbf{n}$ Stage $\mathrm{j}$

EFOR(jn) Forecasting track record of exchange rate function number $\mathbf{n}$ Stage $\mathbf{j}$

GLS Generalized least squares

OLS Ordinary least squares

$\mathbf{R}^{2} \quad$ Coefficient of determination

$R^{-2} \quad$ Corrected coefficient of determination

VAR Variance

Variable(-t) Variable, lagged $t$ periods 